\section{ECONOMICS}

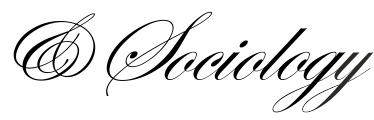

\author{
Tom R. Burns, \\ Department of Sociology, \\ Uppsala University, \\ Uppsala, Sweden, \\ E-mail:Tom.burns@soc.uu.se
}

\section{Philippe DeVillé, Institut De Recherche Économique Et Sociale (IRES), \\ École Des Sciences Économiques \\ De Louvain, \\ Université Catholique De Louvain, \\ Louvain-La-Neuve, Belgium, \\ E-mail: \\ philippe.deville@uclouvain.be}

Received: December, 2016

1st Revision: April, 2017

Accepted: June, 2017

DOI: $10.14254 / 2071-$

789X.2017/10-2/1

JEL Classification: A13, D63
Burns, T. R., DeVillé, P. (2017), Socio-economics: the Approach of Social Systems Theory in a Forty Year Perspective, Economics and Sociology, Vol. 10, No. 2, pp. 11-20. DOI: 10.14254/2071-789X.2017/10-2/1

\title{
SOCIO-ECONOMICS: THE APPROACH OF SOCIAL SYSTEMS THEORY IN A FORTY YEAR PERSPECTIVE
}

\begin{abstract}
This article presents a social systems theoretical approach to the field of socio-economics. Drawing on actor-system dynamics, a social systems theory, developed in the 1970 s, we report on how it has been applied to socio-economic questions and analyses in a series of reports and publications for the past $40+$ years. Among the problems discussed are:

(1) The discontents and conflicts of capitalism.

(2) Economic inequality, uneven socio-economic development, conflict and instability.

(3) The limits of orthodox economic theories and policies in the face of recurrent economic crises and instabilities.

Introduction of the paper briefly outlines the social systems theory, actor-system dynamics (ASD). Part I discusses the continued relevance of the systems approach, possibly even more so as systemic failures have occurred in the post-Keynesian world. In Part II, we consider what next for social systems analysis and its application to socioeconomic problems.
\end{abstract}

Keywords: actor-system dynamics, socio-economics, capitalism, economic inequality, conflict and instability.

\section{Introduction}

Two fundamentally different conceptions of the human being and human action as well as system behavior underlie most modeling of social behavior and social systems. In one, social actors are viewed as essential forces that structure and restructure social systems and the conditions of human activity and development. The individual, the historic personality enjoys an extensive freedom to act within and upon social systems, and in this sense is to some degree independent of them. In the other view, social actors are either not found or are automata following the established rules or given roles and functions in a world which they cannot basically change. Social action and movements as creative-destructive forces are absent.

To a large extent, systems theories have been based on the second view under the influence of the deterministic natural science paradigm; in a certain sense, it is akin to system engineering (e.g., Forrester's system dynamics, 1961, 1968; Klir, 1969; Meadows et al., 1974, among others). This approach tends to ignore or even deny actors freedom of decision and transformative opportunities in much of its system modeling and analysis. System 
sustainability and evolution tend to be considered "natural" and taken for granted, rather than being treated as problematic and subject to social struggle and transformation, possibly even collapse.

Our research since the 1970s has shown that social systems modeling and analysis are compatible with and can readily incorporate concepts relating to the cognitive, decision, and strategic capabilities of social actors as purposeful, self-reflexive, and transformative agents. Such a conceptualization of social actors refer not only to individuals but to social groups, organizations, alliances and nations, which have the capability of reflection judgment and making collective decisions to carry out collective action. The processes and social logic of making decisions and acting could obviously be very different for individuals or small groups as compared to large collectivities.

The more than forty years since our early work has been marked by intense debates, new questions and challenges relating to conceptual and empirical research within the framework of Actor-System-Dynamics (ASD) theory. The aim of this article is to consider three key issues: (i) the theoretical-methodological underpinnings of ASD and its integration of economics and sociology (section 1 below); (ii) the continued relevance of the ASD theoretical and empirical work to several key issues in, and the development of, socio-economics (section 2); and (iii) conclusions: what's next - new challenges and issues (section 3).

\section{The theoretical-methodological-ontological underpinnings}

The ASD research made two major contributions: (A) It expanded and applied a dynamic, actor-oriented systems theory and (B) it developed coherent ways of overcoming the separation between economics and sociology in a new transdisciplinary synthesis, "socioeconomics" (Baumgartner et al., 1975, 1986; Baumgartner et al., 1976; Baumgartner, 1979; Burns, 1990; Burns and DeVille, 2003, 2006; Burns and Flam, 1987; Burns and Roszkowska, 2016).

\subsection{Development and application of a dynamic, actor-oriented systems theory}

The ASD approach addresses, in general, questions about complexity and the organization of complexity in social systems. More specifically, it deals with questions of how socio-economic and other systems function and evolve, how systems interact with one another, how they impact on one another and their environments, and how unexpected outcomes and developments emerge from system processes and interaction. Social systems consist of institutional, cultural as well as material structures. Hence, our research network has early on had a substantial community of "institutionalists", developed rule system conceptions (see below) as a coherent social scientific foundation, and made extensive use of descriptions and analyses of institutions and cultural formations.

In contrast to other systems approaches in the social sciences ${ }^{1}$, ASD theory is based upon the assumption of active, creative, normative (moral), transformative agents (individuals as well as collectives). With the exception of the work of Talcott Parsons (1951) (whose approach nevertheless remained in large part static), most systems approaches (as well as mainstream economics) are largely devoid of systematic agential, cultural and institutional conceptualizations $^{2}$. Actors are conceptualized in ASD theorizing as creative participants in

\footnotetext{
${ }^{1}$ In particular, that of Talcott Parsons (1951) and later Niklas Luhmann (1995) as well as many natural science and engineering approaches (Ludwig von Bertalanffy, 1968; Jay Forrester, 1961, 1968; Klir, 1969), and more recently the group Biomatrix approach (Dostal, 2005), among others.

2 This was to be expected of Bertalanffy, Forrester, and Klir as well as even World System Theory (Wallerstein, 2004) and structural Marxism (Althusser and Balibar, 1970) .
} 
social systems as well as agents of much of the dynamics of the structuring and transformations of these systems.

Key conceptual innovations have been and still are the trademark of ASD theory. First, social beings are creative and self-transforming agents. Human consciousness is viewed in terms of self- representation and self-reflectivity on collective and individual levels. Second, cultural and institutional formations are seen as constituting the major environment of human behavior, an environment in part internalized in social agents in the form of shared rules and systems of rules. Third, interaction processes and games are considered to be embedded in, and context dependent on, cultural and institutional systems that facilitate, constrain, and, in general, influence the actions and interactions of human agents (Granovetter, 1985). Fourth, social systems are conceptualized in ASD in multi-level terms, for instance, as hierarchies of processes where a higher level interaction process sets the functions and parameters of lower level interactions and related processes; this multi-level property is crucial in generating endogenously the dynamics of the system, although of course external forces also produce dynamics (see below). Fifth, ASD social systems are considered to be open to, and interacting with, their environment. Through interaction with their environment and also through internal processes, such systems acquire new properties, and subject to restructuring and transformation, resulting in their evolution and development. Sixth, social systems in the ASD perspective entail complex configurations of tensions and conflicts due to divergent interests and power struggles among groups as well as the contradictions between subsystems and processes. And seventh, rule systems (the bases of institutions and cultural formations) evolve as a function of (a) human agency realized through interactions and games and (b) selective mechanisms in part, constructed by social agents in forming and reforming institutions but also, in part, a function of physical and ecological environments.

The ASD conception of social rules and rule systems is a major innovation in this and related work (Burns et al., 1985; Burns and Flam, 1987; Burns and Hall, 2012). Social rule systems and rule processes are universal in human groups and organizations and are the building blocks of institutions and cultural formations; they are produced by and embodied in the practices of groups and collectivities of people: language, customs and codes of conduct, norms, laws, and the social institutions of family, community, state, and economic organization such as business enterprises and markets. Most human social activity - in all of its extraordinary variety - is organized and regulated by socially produced rules and systems of rules. Rule processes - the making, interpretation, and implementation of social rules as well as their reformulation and transformation - are often accompanied by conflict and struggle among agents, and the mobilization and exercise of power. Social rules and rule regimes - and the formation and reformation of rule systems - are, therefore, not transcendental abstractions in the ASD perspective.

In this perspective, human agents (individuals, groups, organizations, communities, and other collectivities) are seen to interpret, adapt, implement, and transform rules, sometimes cautiously, other times radically (Burns and Dietz, 2001). Such behavior explains much cultural and institutional dynamics. Major struggles in human history revolve around the formation and reformation of core economic, administrative, educational, and political institutions of society, the particular rule regimes defining social relationships, roles, rights and authority, and obligations and duties as well as the general "rules of the game" in these and related domains of social action.

Of particular interest in the context of our approach is the concept of meta-power, based on the capability to shape and reshape institutional arrangements, the rules of the game, the access of actors to key resources and corridors of power. Exercise of such power is 
observable in the struggles to maintain or change socio-economic and other societal systems (Burns et al., 1985; Burns and Flam, 1987; Burns and Hall, 2012).

\subsection{The synthesis and integration of economics and sociology (as well as history and political economy)}

The ASD conceptualization laid out the foundations for theoretical as well as empirically oriented research. The theoretical framework was used to analyze a variety of scientific and policy problems from a multi-disciplinary and dynamic perspective: the complex interplay between economic and socio-political institutions, conflicts and struggles over economic resources and economic institutions, problems of development and underdevelopment, and inflation and unemployment. The research resulted in a number of publications (from the 1970s (Baumgartner et al., 1975; Baumgartner et al., 1976; Baumgartner, 1977; Baumgartner, 1979; Burns et al., 1979; DeVille and Burns, 1976)); in the 1980s (Baumgartner et al., 1986; Burns et al., 1985; Burns and Flam, 1987), and more recently (Burns, 1990; Burns and Deville, 2003, 2006; Burns et al., 2013; Burns and Roszkowska, 2016; Carson et al., 2003).

Much of the research dealt, in some sense, either with social power, conflict, and struggle regarding economic resources and institutions or the structural and other factors which underlie powering, conflict, and struggle in relation to economic agents, processes, and institutional arrangements (Burns and Hall, 2012).

- Conflict over institutions and policies and over the distribution of resources, particularly economic and political resources.

- The structural bases of economic inequality and conflict - and their instability.

- The shaping and reshaping of socio-economic institutions and the contradictions and conflicts and instabilities which such developments evoke.

- The failure of orthodox economic theories, including to some extent Keynesianism, in the face of recurrent economic crises and instabilities.

The various topics of ASD research relating to socio-economic issues differentiate our work markedly from that of mainstream economics (Baumgartner et al., 1976; Baumgartner et al., 1986; Burns et al., 1985; Burns et al., 2013). The ASD approach to human behavior does not rely on the axiomatic of rational choice theory. Our basic assumptions are in large part incompatible with the usual narrow homo oeconomicus behavioral assumptions - that is, in brief, perfect foresight, perfect knowledge and perfect information about the available choice sets and their elements, and the capacity to optimize on the part of individuals and collectives (Baumgartner et al., 1986; Burns and Roszkowska, 2016). On one side, mainstream economic assumptions are more encompassing, on the other, they are more restrictive. As indicated above, social actors (individuals as well as collectives) are in ASD theory active, self reflective, creative, normative (morally conscious), and transformative agents. But they exhibit also imperfect information, limited knowledge, unequal powers, myopic foresight, and "irrational behavior". In addition, they may be faced with "radical uncertainty" (Frank Knight, John Maynard Keynes) and limited capacity to compute. All of these assumptions are close to the "bounded rationality" assumption argued by Herbert Simon (1969). Such a conception lends support to our treatment of economic processes in behavioral, conflictive and powering terms. It enables ASD investigations to address issues such as the mobilization and exercise of power in shaping and constraining institutional development, blocked or distorted development, and socio-economic crises and their dynamics (Baumgartner et al., 1977, 1986; Burns and DeVille, 2006; Burns et al., 2013).

At the same time, it has been somewhat unusual for sociologists and other social scientists to consider topics such as inflation, the structuring and restructuring of markets, the 
shaping and reshaping of entire economic systems; in addition, the development and functioning of alternative socio-economic systems such as the former Yugoslavia, the facilitators of and constraints on technology transfer, the wealth and poverty of nations, among other socio-economic topics and issues. From the start our team (economists and sociologists) conducted jointly early trans-disciplinary research on these and related topics and issues, which as we suggest below continue to be relevant and challenging 40 years later (Burns and DeVille, 2003, 2006; Burns and Flam, 1987; Burns and Hall, 2012; Burns et al., 1979).

We recognize that the predictive capability of our models, in the usual sense, is very limited. However, aside from some very short-run predictions, traditional economic models have not scored very well either, especially when economies have been faced with brutal shocks, structural failures and institutional incoherence and degeneration. We felt, however, that our framework might prove itself fruitful in many ways, allowing for the identification of capabilities and major systemic mechanisms and for predicting system potentialities and limitations in a range of situations. It also enables us to identify key social agents involved, their capabilities and potentialities, their social judgments and likely choices, their strategic behavior leading to inflationary, contracting or other economic pressures, and to constraints on such processes. Socio-economic developments are not, in the ASD perspective the result of blind, mechanistic forces but the result to a substantial degree of human individual and/or collective actions - based on good as well as bad judgments - even in cases that concern institution building and reform.

In sum, ASD conceptualizations and analyses are contributions not only to the development of social systems theory and methodology but to socio-economic theorizing and analysis. The latter has failed often in the past to conceptualize power and conflict processes, institutional arrangements and their dynamics and transformations, the evolution of socioeconomic systems, and a great deal of dynamic non-equilibria phenomena.

\section{The Continued Relevance of the ASD approach}

In reviewing this work, we find ourselves surprised at what appears to us and to many of our scientific colleagues, a substantial evidence of the relevance of many of the topics and issues that were analyzed from 40 years ago to the present time.

Capitalism and its discontents continue more than ever (Baumgartner et al., 1986; Burns and DeVille, 2006; Burns and Hall, 2012; Burns et al., 2013; DeVille and Burns, 1976). Conflicts and struggles are endemic on all levels and in all sectors, not only on labor markets but commodity and money and financial markets. Power, conflict, and institutional analyses continue to be relevant to specific socio-economic systems, as we tried to show in earlier studies in the cases of Belgium, Mexico, the former Yugoslavia, and Latin America (Baumgartner et al., 1986).

Socio-economic development continues to be highly uneven (with well supported development in some cases and blocked or distorted development in others (Baumgartner et al., 1976; Baumgartner et al., 1986). There is not only a wealth but a poverty of nations, regions, and sectors. This is the consequence of capitalist logic and related institutions as we have come to know, producing inequality and uneven development along with its massive outputs and flows of goods and services (often at the expense of degrading societal conditions as well as the natural environment).

Much of our research was devoted to the analysis of inflation and its causes, an issue of great scientific and policy concern during the 1970s. Eventually, advanced economies found ways to regulate inflation, shifting from accommodation to wage, price, and taxation demands, on the one hand, to a monetarist regime which focused on regulating credit to households, enterprises and government, on the other hand. At the same time, developing 
countries such as China, Korea, Taiwan were and still are exporting relatively cheaper although increasingly sophisticated commodities to advanced economies, helping the latter to constrain their inflationary pressures.

As we have argued since the early 1980s, conflicts and struggles over income distribution issues generate inflationary pressures in such countries as Belgium, Iceland, Italy or Sweden, but particularly in developing countries with limited economic and political means to deal with and mitigate those tensions and conflicts. Our central argument has been that monetarism could not counter inflationary pressures because it could not address the underlying distributional conflicts (see, for instance, Baumgartner et al., 1986, p. 89). During a long period of money and credit creation, inflation could in most instances be kept at relatively low levels because it contributed to mediating societal tensions and conflicts. Only after the highly destabilizing crisis of 2007 and afterwards, do we see the imposition once again of powerful constraints, especially in Europe, leading to the introduction of austerity policies, thereby intensifying competition and conflict potentials, as experienced by Greece, Italy, Spain, and Portugal, among others. Modern democratic governments are only able to a limited degree to address directly the conflicts over income distribution among societal groups as well as economic sectors and government agencies. Their best strategies have been accommodation to demands (from private companies, government agencies, and households) by expanding government budgets, subsidies, and debts contributing to inflation as it took place from the late 1960s to the early 1980s and by allowing from the 1970s on for the massive expansion of credit for households and businesses. That policy mix reached its limits by 2010 when the sovereign debt became a central issue in Europe. Nowadays, international banks and the IMF impose "austerity measures" on several European countries, often in the context of weakened political leadership, shrinking resource base, and continually rising expectations and demands. Recent events in several of these countries are signs of increasing tensions and conflicts, as is the case in, for example, France, Italy, Spain, and Portugal.

After the appearance of the ASD 1986 book (Baumgartner et al., 1986), the former Yugoslavia dissolved (early 1990s). Already, our research had identified the underlying crisis, related conflicts and their socio-economic impacts (see Baumgartner et al., 1986, Chapter 7). The inability of the Yugoslav political elite to deal with these and related crises became blatant. This was the context that led to the dissolution of this nations and the wars, destruction, and mass murder that followed.

In Latin America, while the powerful pressures producing inflation continued (and continue), dramatic changes have taken place. Many Latin American countries have made considerable progress toward more democratic orders: Argentina (1983), Bolivia (1982-85), Brazil (1985), Chile (1989), Paraguay (1991-2), Uruguay (1984), among others. However, increasing economic as well as political problems since 2010 are generating increasing instability and uncertainty and the likelihood of failing states and failing economies.

As emphasized in our work over several decades, the internationalization of the complex capitalist system over the world has not contributed in a significant way to the "convergence" among countries of socio-economic conditions or of the majority of their populations. The production and reproduction of inequality, unequal exchange, and uneven development are still present. While sustaining substantial inequality in the wealth and poverty among nations, it does allow also for the advancement of some, such as the BRIC countries (see below). The following are relevant historical developments.

- The New International Economic Order (NIEO) was historically a major concept pushed by developing countries (for instance, the Group 77 (1964) and the United Nations General Assembly (1974). However, this normative idea had insufficient real power mobilization behind it at the time. Interestingly, in the meantime, the emerging BRIC nations (Brazil, Russia, India, and China) have not only ideas about a new 
international economic order but begin to mobilize global power to push effectively for it. Under their influence, there are emerging strategies and pressures in that direction.

- The ASD approach has also been applied to an analysis of financial systems as complex, dynamic and unstable systems (Burns and DeVille, 2003; Burns et al., 2013; Burns, 2017). The 2007+ crisis has been analyzed as a systemic crisis; it is argued that a major re-design will be required if genuine stabilization is to be achieved (Burns, 2017; Burns et al., 2013). But such a re-design is unlikely to happen in the present context, given the opposition of major world banks and financial interests and their supporting countries. Nevertheless, the need remains and will be with us for some time. We will probably have to wait for the occurrence of the next major crisis (within the coming 5-10 years for the global system of banking and finance to be seriously confronted and potentially subject to substantial reform.

- With respect to the issue of ecological sustainability, DeVille and Burns (1976) had already suggested in the mid-1970s that the major factor undermining capitalism would not be class and related societal struggles but ecological and natural constraints (class and other struggles appeared intense in the 1960s and 1970s and made up the historical context of much of what was written in ASD reports and publications). This prediction, based on ASD systemic analyses seems to be more pertinent than ever.

\section{Conclusions: What next - Challenges and issues?}

Major challenges remain. We and others must keep expanding and elaborating social system theory, ASD in particular, in the face of the terrible fragmentation of knowledge and the frustrating and costly inability to address with systematic knowledge and analysis many current problems in socio-economics and areas of social science and policy. The currently increasing violence both among and within countries testifies to the urgent need to have a better integrated, encompassing but coherent social science to identify and make proposals to deal with the many dangers which are threatening the future of humanity. ASD theory remains a promising basis for such a development. Social systemic analyses pinpointing the drivers and dynamics of links and processes are on the one hand needed, and at the same time should be expanded beyond socio-economics and political economy.

A significant part of ASD research, which has been addressed to social scientists concerned with socio-economic issues, institutions, and development, is based on what was a new social system theory at that time (from the 1970s). For the future, the need for further linking up with other social sciences such as anthropology, cultural geography, and history as well as the humanities (philosophy, linguistics, literary analysis, etc.) is clear. Moreover, closer linkages must be accomplished between the social sciences and humanities, on the one hand, and the natural, bio-medical and engineering sciences, on the other hand. The "tower of Babel" metaphor ([8]) applies today as much as then (the 1980s), if not more so. The task at hand for upcoming research is on the further elaboration of the theory of actor-system dynamics beyond its socioeconomics comfort zone. It should develop its potentiality as a powerful tool of systematic analysis of complex, dynamic social systems and their interaction with technological as well as ecological systems, thus linking social, natural and engineering sciences (Burns et al., 1985; Carson et al., 2009).

Today we are faced with something described elsewhere as the "perfect storm" of social systems. Unstable financial systems, ineffectual global institutions, declining welfare and increased inequality, failed states, warring regions, widespread terrorist activity, and increasing environmental degradation are destabilizing the existing international order. The world is faced with serious and immediate ecological disturbances and, in some cases, 
irreversible destruction, all this feeding into vicious circles of social violence and further social and ecological degradation (this is an adaptation of a remark by Paul Ehrlich). Technological advances, especially in communication technologies, are deeply transforming interpersonal relations and the production of information. The traditional representative democratic institutions are put in question as an efficient mechanism for expressing the various claims and proposals emerging from large segments of the population. This has been fed by increasing perverse nationalism supported by new powerful right wing populist movements. The results have been more racial discrimination, social exclusion and attempts to restrict civil liberties. Cleavages and struggles at the international as well as other levels are much deeper and the basis or potentialities for shaping global consensus less feasible than earlier in the case of many advanced nation-states or emerging and developing nations. Moreover, as it was already true 40 years ago, there are powerful vested interests and antagonistic nation-state regimes opposing appropriate initiatives and transitions. This calls for at least three key lines of research.

First, it is imperative to understand the inner structure of these complex systems and the roots of their dynamic, destabilizing behavior, their cycles, and local-global strategic linkages. It is essential to further develop the necessary scientific and policy capacities to respond to and operate on them on a medium to long-term basis. In the face of diverse, complex social systems -government, finance systems, socio-technical systems, regional systems, and the global system -in disarray and unstable, we are convinced that the conceptual and methodological toolbox which ASD offers, is more than ever potentially useful.

Second, we need multi-disciplinary, global scientific analyses of capitalisms - its socio-economic and political foundations, its variants, and its threats to social and economical conditions and development. There is a related need to identify and assess alternative capitalisms, their positive and negative performance patterns and development tendencies, identifying one or more forms (if any) that would likely be compatible with ecological sustainability, people's welfare, and conditions of justice and social order.

Third, at the same time, the scope of ASD requires several extensions. As we wrote in the 1980s (see Baumgartner et al., 1986, p. 91), the major challenge for promoting and implementing appropriate societal transformation, in particular the creation of coherent world level governance institutions, is to overcome the lack of available institutional designs and means. Institutional design, selection, and implementation are consequently key research processes to cope with these issues. In light of our arguments, we came to pessimistic conclusions in 1986 (which we continue to express): the necessary transformation of international conditions and regimes will probably have to await a much more profound crisis (1986; repeated, November, 2016). But, we also know the dangers and the appalling human costs of another catastrophic crisis that is most likely to take place at the world level. As social scientists, it is our responsibility to develop tools and analyses to avoid or mitigate as much as possible such a catastrophe.

\section{References}

Althusser, L. and Balibar, E. (1970). Reading Capital. London: New Left Review.

Von Bertalanffy, L. (1968). General System theory: Foundations, Development, Applications. New York: George Braziller.

Baumgartner, T., Burns, T. R. and DeVille, P. (1979). Work, Politics, and Social Structuring under Capitalism: Impact and Limitations of Industrial Democracy Reforms Under Capitalist Relations of Production and Reproduction. In: T. R. Burns, L. E. Karlsson, and V. Rus (eds.), Work and Power. London: Sage. 
Baumgartner, T., T. R. Burns and DeVille, P. (1977), The Oil Crisis and the Emerging World Order: The Structuring of Institutions and Rule-Making in the International System. Alternatives: A Journal of World Policy, 3, 75-108.

Baumgartner, T., Burns, T. R. and DeVille, P. (1975). The Structuring of International Economic Relations. International Studies Quarterly, 19, 126-159.

Baumgartner, T., Burns, T. R. and Meeker, D. (1976). Toward a Systems Theory of Unequal Exchange, Uneven Development, and Dependency Relationships. Kybernetes, 5, 15-23.

Baumgartner, T., Burns, T. R. DeVille, P. (1986). The Shaping of Socio-economic Systems: The application of the theory of actor-system dynamics to conflict, social power, and institutional innovation in economic life. London/New York: Gordon and Breach.

Burns, T. R. (1990). Models of Social and Market Exchange: Toward a Sociological Theory of Games and Human Interaction. In: D. Calhoun, M. W. Meyer, and W. R. Scott (eds.). Structures of Power and Constraint: Essays in Honor of Peter M. Blau. New York: Cambridge University Press.

Burns, T. R., Baumgartner, T. and DeVille, P. (1985). Man, Decisions, and Society. New York/London: Gordon and Breach.

Burns, T. R., and DeVille, P. (2003). The three faces of the coin: A socio-economic approach to the institution of money. European Journal of Economic and Social Systems, 16(2), 149-195.

Burns, T. R. and DeVille, P. (2006). Dynamic Approaches in Social System Theorizing. Handbook of 21st Century Sociology. Thousand Oaks, CA: Sage.

Burns, T. R. and Dietz, T. (2001). Revolution: An evolutionary perspective. International Sociology, 16(4), 531-555.

Burns, T. R. and Flam, H. (1987). The Shaping of Social Organization: Social Rule System Theory with Applications. London: Sage.

Burns, T. R. and Hall, P. (2012). The Meta-power Paradigm: Impacts and Transformations of Agents, Institutions, and Social Systems - Capitalism, State, and Democracy in a Global Context. Frankfurt/NewYork/Oxford: Peter Lang.

Burns, T. R., Karlsson, L. and Rus, V. (eds.) (1979). Work and Power. London: Sage.

Burns, T. R. (in collaboration with P. DeVille and A. Martinelli) (2017). Boom and Bust Cycles in Financial Markets - Causes and Cures: Multiple Contradictory Functions of Money and Collective Action Problems. Theoretical Economics Letters, 7, 914-928.

Burns, T. R., Martinelli, A. and DeVille, P. (2013). A Socio-economic Systems Model of the Global Financial Crisis of 2007+: Power, Innovation, Ideology, and Design Failure. In: J. Pixley and G. Harcourt (eds.). Financial Crises and the Nature of Capitalist Money. London, Palgrave/Macmillan.

Burns, T. R. and Roszkowska, E. (2016). Rational Choice Theory: Toward a Psychological, Social, and Material Contextualization of Human Choice Behavior. Theoretical Economics Letters, 6 (April \#), 195-207.

Carson, M., Burns, T. R., Calvo, D. (eds.) (2009). Paradigms in Public Policy: Theory and Practice of Paradigms Shifts in the EU. Frankfurt/Oxford/New York: Peter Lang.

DeVille, P. and Burns, T. R. (1976). Institutional Responses to Crisis in Capitalist Development. Social Praxis, 4, 5-46.

Dostal, E. (in collaboration with A. Cloete and G. Jaros) (2005). Biomatrix: A Systems Approach to Organizational and Societal Change. $3^{\text {rd }}$ ed. Capetown: Imaging Data Solutions.

Forrester, J. (1961). Industrial Dynamics. Cambridge: MIT Press.

Forrester, J. (1968). Principles of Systems. Cambridge: MIT Press.

Granovetter, M. (1985). Economic action and social structure: The problem of embeddedness. American Journal of Sociology, 50, 481-510. 
Klir, G. (1969). An Approach to General Systems Theory. New York, Van Nostrand Reinhold.

Luhmann, N. (1995). Social Systems. Translated by John Bednarz with Dirk Baecker. Stanford, Calif.: Stanford University Press.

Meadows, D. H., Meadows, D. L., Randers, J., Behren, II, W. (1974). Limits to Growth. $2^{\text {nd }}$ ed. New York: Universe Books.

Parsons, T. (1951). The Social System. Glencoe, IL: Free Press.

Simon, H. A. (1969). Sciences of the Artificial. Cambridge: MIT Press.

Wallerstein, I. (2004). World-systems analysis. Durham, NC: Duke University Press. 